Res Pública Revista de Historia de las Ideas Políticas

ISSN: $1131-558 \mathrm{X}$

https://dx.doi.org/10.5209/rpub.75979

\title{
Jacques Lezra: posición defectiva
}

\author{
Claudio Aguayo Bórquez ${ }^{1}$
}

Recibido: 07-05-2021 / Aceptado: 16-09-2021

Resumen. En el presente ensayo, me propongo interrogar el concepto de posición a partir de las reflexiones del pensador Jacques Lezra sobre la llamada institución defectiva. El trabajo de Lezra se encuentra atravesado por una serie de situaciones conceptuales en torno a lo que conocemos como modernidad temprana, pero también por el pensamiento de Maquiavelo, Marx y Althusser. En torno a este último, intento tejer aquí el nudo de una reflexión sobre la posicionalidad como un "coup de force" (Derrida) o una violencia primaria, atómica, que tiene el sello de una desviación puntual, de una violencia mínima. Esa violencia desviante es la que permite pensar el comienzo como curvatura y la institución como defecto -en contra de la mediación hegeliana, que la asume como suplencia de una deficiencia ontológica. Finalmente, interrogo, a partir del cruce Lezra-Deleuze, la posibilidad de un sadismo de la contingencia para pensar la violencia de esta posicionalidad defectiva, en tanto clave para un pensamiento de la coyuntura constituyente.

Palabras clave: institución defectiva; golpe de fuerza (coup de force); posición; curvatura; tautología.

\section{[en] Jacques Lezra: Defective Position}

Abstract. Through this essay I intent to interrogate the concept of position departing from Jacques Lezra's thought about what he called "defective institution(s)". Lezra's work is evidently traversed by a series of conceptual situations surrounding what is known as early modernity, but also by thinkers like Machiavelli, Marx and Louis Althusser. It is about this last name that I try to weave the reflexive knot about positionality as "coup de force" (Derrida), a primary violence, atomic, with the seal or stamp of a punctual deviation, or minimal violence. This deviant violence is which allows me to think the commencement as curvature and the institution as defect-against Hegelian mediation that assumes institution as supplement for an ontological, previous deficiency. Finally, I inquire, by crossing Lezra and Deleuze, the possibility of a contingent sadism to think the violence of this defective positionality, as an important element to think the constituent conjuncture.

Keywords: Defective Institution; coup de force; Curvature; Position; Tautology.

Cómo citar: Aguayo Bórquez, C. (2022). Jacques Lezra: posición defectiva. Res Pública. Revista de Historia de las Ideas Politicas, 25(2), 41-48.

Quapropter locus est intactus inane vacansque.

Quod si non esset, nulla ratione moveri ${ }^{2}$. Tito Lucrecio Caro, De rerum natura

La violencia divina, que es insignia y sello, jamás medio de ejecución sagrada (heiliger Vollstreckung) puede llamarse la soberana (waltende) Walter Benjamin, Zur Kritik der Gewalt

En su ensayo sobre El príncipe de Maquiavelo (titulado, siguiendo una forma conceptual lucreciana, "Corpora caeca”) Jacques Lezra enuncia lo que es quizás uno de los más importantes gestos de su obra, deconstructiva, llena de recovecos, pero sujeta a momentos de un minimalismo intensivo - como diría el propio Lezra, a una cierta violencia mínima, atómica. "La fortuna, la fortuna elemental -escribe Lezra- es el nombre irreductible, indivisible y efectivo que damos a una fuerza que consti- tuye [esta] clase de conceptos defectivos, [ella] trabaja a través de El príncipe de modo indexal, ostensivo" ". El gesto, por excelencia, al que me refiero aquí consiste en una zona de densidad literario-epistemológica. La violencia de la fortuna, de la fortuna que divide El príncipe, la obra de Maquiavelo -y ello podría incluir evidentemente la fortuna de su escritor, torturado y caído en desgracia poco antes de la dedicatoria del libro- es la fortuna, también, que se intenta describir: es decir, el concepto abstracto de fortuna. Esa fortuna, la fortuna de las letras -los átomos lucrecianos-que componen la obra de Maquiavelo, la fortuna de los gestos que acompañan a la obra, su estructuración en tanto conminación y llamado y al mismo tiempo el intento de definición del campo político, son también la fortuna que viene aquí a discutir con Boecio, con Gracián, con Cavalcanti su estatuto y su rol en torno a la virtù. Para mí, este ges-

\footnotetext{
University of Michigan

claguayo@umich.edu

Para una traducción del epígrafe del presente ensayo -y más allá de él- cf. nota 47.

J. Lezra, Corpora Caeca: Discontinuous Sovereignty in The Prince, Manuscrito enviado por el autor, pp. 6-7. 
to de Lezra es crucial: se trata de la radicalización de un "principio" deconstructivo, en el sentido de un "plus de metáfora"-no es casual que "La mitología blanca" de Derrida termine aludiendo al heliotropo, a "una piedra; piedra preciosa, verdosa y rayada de venas rojas, especie de jaspe oriental"4. La escritura de Lezra va, posiblemente, al encuentro de esas materialidades, esas piedras -preciosas o no, más vale decir defectuosas en este caso- que son desarticulantes respecto de los ideologemas clásicos del sentido, la definición, y sobre todo, del concepto hegeliano del concepto y sus posibilidades cuasi-infinitas de subsunción. Por eso muchas veces se compone como palimpsesto y como superposición de metáforas conceptuales. Ya que el trabajo de Lezra se caracteriza por una diversidad de zonas de inscripción, quisiera retomar aquí tres problemas íntimamente imbricados en la obra de nuestro autor: los problemas de la institución/lo instituyente, la comunidad sadeana y la tautología-política $-y$ su relación necesariamente desvinculante con la teología-política. Ello para llegar a una nueva lectura del problema de lo constituyente, evitando el término "poder" que valorizó Toni Negri y reemplazándolo por el de "momento", "situación", "estado de cosas" o, para usar un 'althusserianismo' que le es propio al trabajo de Lezra, coyuntura constituyente 5 .

\section{1.}

Quisiera partir aquí con una referencia aparentemente externa al trabajo de Jacques Lezra. Se trata de un problema propuesto por el autor chileno Fernando Atria, de espesa influencia hoy día en el campo de debate sobre el actual proceso constituyente que vive el país sudamericano. Como intelectual, Atria se ha esforzado en retrotraer el debate constitucional hacia al menos dos cuestiones que están en el corazón de los esfuerzos lezreanos: nos referimos a los tópicos de la institución, de la democracia institucional o de los derechos basados en instituciones, y el republicanismo ${ }^{6}$. En torno al último problema, evitaremos ahondar señalando que la tradición republicana reivindicada por Atria pertenece al orden de un republicanismo normativo, más cercano a

J. Derrida, "La mitología blanca, la metáfora en el texto filosófico", en Márgenes de la filosofia, trad. C. González Marín, Madrid, Cátedra, 2008, p. 311. Nótese que aquí lo decimos de pasada, pero los conceptos, para Derrida - como ha demostrado la publicación reciente de su seminario La vie la mort- constituyen siempre metáforas conceptuales, operaciones de traducción/traslación/superposición. La teoría se constituye antes que todo como un palimpsesto metafórico, metáfora de metáforas. Cf. también "The Retrait of Metaphor" en Pysche, Inventions of the Other, Vol. I, California, Stanford University Press, 2007.

5 A. Negri, El poder constituyente, trad. S. Frabotta y R. Sánchez Cedillo, Madrid, Traficantes de sueños, 2014, p. 88. El trabajo de Negri se habría caracterizado por una devolución del problema constituyente a la institución no-defectiva, binómica de la metafísica: “a la virtud se le opone la fortuna, a la producción el producto, a la fuerza constituyente la fuerza constituida".

6 F. Atria, "Sobre la soberanía y lo político", Derecho y humanidades, 12,2006 , pp. 47-93. Sobre la relación entre constitución, momento constituyente y excepción, Atria reconoce en este artículo que el "republicanismo cívico parece estar en mejor posición que el liberalismo, porque para el republicanismo la relación entre la constitución y lo político es interna". los "Federalist Papers" de Madison, Hamilton y Jay, y a lo que Pocock ${ }^{7}$ llamó "tradición republicana atlántica", que a Maquiavelo y la construcción de una temporalidad republicana abierta al conflicto ${ }^{8}$. En Materialismo salvaje Jacques Lezra ya ha reparado en los límites del republicanismo normativo proponiendo un republicanismo material, salvaje, cuya consistencia residiría, precisamente, en sus capacidades no-adaptativas de abrirse a un tipo de alteridad material que es irreductible a la esfera de la ley, la división de poderes y el "deseo de no-dominación" como norma de la libertad, enfatizado por autores como Philip Pettit ${ }^{9}$ o Miguel Vatter ${ }^{10}$. Atria, destacado profesor de derecho constitucional y uno de los impulsores del "giro schmittiano" del constitucionalismo chileno -junto con Renato Cristi- adscribe en variadas ocasiones al republicanismo normativo basado en la definición negativa de libertad como deseo de no dominación proporcionada por la tradición atlántica. Sin embargo, el punto que me interesa a la hora de conectar el núcleo de interrogantes de la obra de Atria y el materialismo de Jacques Lezra -y encontrar, quizás en esta conexión, lo que podrían ser algunas respuestas al atolladero epistemológico del "momento constituyente" chileno- es su recurrente uso del concepto de institución ${ }^{11}$. Para explicar la necesidad de un nuevo momento constitucional en Chile -años antes del agotamiento del neoliberalismo pinochetista y su constitución jurídicomaterial-Atria recurrió a la idea de "forma institucional extraordinaria"12. El momento constituyente no podría prescindir de esta institucionalidad extraordinaria, que tiene la forma de una paradoja o un oxímoron, en la medida en que funciona como la forma institucional que puede, mediante la encarnación de una voluntad, institucionalizar lo contrainstitucional, la revuelta $-\mathrm{O}$, como el propio Atria ha señalado, tomando prestado un término de Agamben, el momento destituyente ${ }^{13}$. Se trata desde luego de transformar un momento contrainstitucional extraordinario en una serie de formas institucionales que a las que se les pueda imputar una voluntad.

J. Pockock, El momento maquiavélico, trad. E. García López y M. Vázquez-Pimentel, Madrid, Tecnos, 2002.

Para una lectura de Maquiavelo alejada del republicanismo clásico, véase, por ejemplo: "Vida y tiempo de la república" del maquiaveliano argentino Sebastián Torres (2011). Me permito aquí remitir también a mi libro Los tiempos y las cosas. Ontología y política en Nicolás Maquiavelo, Santiago de Chile, Doble Ciencia Editores, 2020.

9 En particular en P. Pettit, Republicanism: A Theory of Freedom and Government, Oxford, Oxford University Press 1997.

10 Las tesis de Vatter son especialmente importantes si se leen a contrapelo del trabajo de Jacques Lezra, quien ha traducido además el texto que da título al libro de Vatter (Form and Event, de Carlo Diano). Con Maquiavelo, señala Vatter, "la prioridad de la forma es negada en la vida política". Esta prioridad del evento por sobre la forma induce otro tipo de tesis sobre la materia como aquello que no se puede contar/simbolizar. Cf. M. Vatter, Between Form and Event: Machiavelli's Theory of Political Freedom, Países bajos, Springer Netherlands, 2000, p. 109 ss.

11 Hallable no sólo en el texto que vamos a citar aquí. Atria ha hablado múltiples veces de una "teoría general de las instituciones" que estaría en la base de su pensamiento.

12 F. Atria, op. cit., p. 86.

13 Cf. la columna reciente de Fernando Atria en el diario chileno "La Tercera". Consultada el 1 de noviembre de 2020: https://www.latercera.com/opinion/noticia/convergencia-de-las-fuerzas transformadoras/RPDIZYRW2JA43EWFHPUWVJXCWA/ 
La jugada teórica de Atria nos conduce a un tipo de pensamiento habitado por viejos binomios que, sin embargo, producen una reactivación de la discusión al interior de un campo más o menos muerto, que ha proliferado en resultados teóricos polémicos para la izquierda chilena: la necesidad de un "esfuerzo de imaginación institucional" que pueda superar los atolladeros de los "socialismos reales", la idea de un "socialismo hayekiano" que respete el orden espontáneo del mercado garantizando derechos ${ }^{14}$, la distinción estricta entre política y derecho como ámbitos irreductibles, y sin embargo sujetos a una mediación y finalmente la posibilidad de leer la "imaginación institucional" como compensación de un déficit preinstitucional ${ }^{15}$. "Institución" en tal caso, sería el nombre de una mediación específica entre un orden espontáneo, irregular, y la norma -el derecho. Desde esta perspectiva, a la institución le sería coextensiva la necesidad de traducir o mediar, sería el objeto y el producto, el umbral específico de la mediación. La "gramática institucional", señala Atria, constituye la garantía misma de que en primer lugar las ideas abstractas de libertad o igualdad que están en la base de la igualmente abstracta idea de socialismo puedan derivar en un orden específico y, en segundo lugar, la garantía material de que las ideas de igualdad o democracia no deriven en formas perversas de supresión mayoritaria o estatista. Sin embargo -y aquí está la dificultad que nos presenta el autor- los conceptos políticos son "preinstitucionales" y "reflexivos" que requieren una materialización concreta. La materialidad de lo político, para Atria, permanece intraducible al derecho. De ahí que podamos considerar, a partir del trabajo de Jacques Lezra, la posibilidad de leer la institución como un problema de traductibilidad entre lo político y lo jurídico.

En torno a esta palabra crucial -institución, institucional, etc.- Lezra ha señalado al menos dos cosas que quiero retomar en este difícil diálogo entre el socialismo hayekiano, liberal o libertario de Atria y el materialismo/ republicanismo salvaje. Lo primero es a propósito del concepto de institución defectiva. Situado no en torno al acto de una fundación estable, al acto de una mediación, sino de una situación contingente a la que llamamos institución, el materialismo de Lezra se rehúsa a entender la gramática institucional -cabe preguntarse si equiparable con lo que Atria entiende por "imaginación” institucional- como el ordenamiento de una serie de situaciones estables, autosuficientes, intimidantes. Las instituciones de Lezra son de este modo "objetos contingentes" y para entenderlas debe tenerse en cuenta no sólo la contingencia de los "futuros estados o resultados [de la institución], sino, de modo aún más extraño, su inscripción en

14 Respecto a esta tesis, a primera vista estrafalaria, pero fundamental como punto de bifurcación del debate constitucional de la izquierda chilena -en cierto sentido, se puede considerar a Atria como el intelectual más importante del frenteamplismo, una forma política derivada de las movilizaciones estudiantiles de 2011, primera vez en que la consigna de Asamblea Constituyente apareció en la escena pública con una fuerza mesurada -cf. "Socialismo hayekiano", Revista de Estudios Públicos, 2011, pp. 49-155.

15 F. Atria, Razón bruta, edición digital, 2018.

16 Ibidem, p. 86. estados de cosas presentes, y, más contraintuitivamente, estados de cosas pasados"17. Las instituciones defectivas, señala el autor, "sujetan la tautología a la solución contingente, las instituciones son heterólogas, y los juicios concernientes a ellas son heterológicos". Se trataría entonces de leer la seguridad de la gramática institucional como afectada por una contingencia constitutiva, asediada, para usar un término derrideano, por formas contrainstitucionales que le son propias al acto mismo de su institución -en el sentido verbal de instituir una institución. Las distinciones clásicas, binómicas, entre política y derecho, entre justicia y ley, entre lo originario y lo derivado ${ }^{18}$ quedarían irremediablemente afectadas así por una heterología que le es inherente al acto mismo de enunciar la ley. Contingencia radical o "materia incontable"19, de lo que se trata es de leer lo defectivo inestable en las pretensiones de estabilidad de todo cuerpo jurídico y político. Desde luego, esta idea confirma un derrideanismo, en la medida en que la decisión y lo indecidible, la institución y lo contingente, etc., "participan de forma impura, contaminante, negociada y bastarda y violenta" 20 . Es esta contaminación originaria la que de hecho habilita a pensar la co-institución entre institución y defecto. En este punto el gesto de Jacques Lezra avanza, sin embargo, en una dirección más compleja, ofreciéndonos los prolegómenos de un pensamiento sobre una situación instituyente abierta a lo defectivo, la posibilidad de pensar instituciones defectivas que no renieguen de esta contaminación inicial. La provocación específica aquí consiste en pensar un concepto que nos permita entender tanto la contaminación inicial como la defectividad inherente a la gramática institucional, el concepto de violencia.

\section{2.}

Es en torno a la apertura de este significante que se abre lo que considero el aspecto más alucinante -en el sentido terapéutico, psicoanalítico y laudatorio del término- del trabajo de Jacques Lezra. Es la vinculación del momento institucional o instituyente con un tramo indivisible, tautológico, el que de hecho al mismo tiempo enuncia las pretensiones de identidad cerrada del concepto de institución -y de cualquier otro concepto: recuérdese lo que mencioné al principio, la gestualidad epistemológicoliteraria-política de Lezra- y su contra-afección por un momento que le es excéntrico. Sin esta asunción radical de una violencia originaria, lo que tenemos, en cambio, es la teología política.

Pauso un poco en el término schmittiano por excelencia para mostrar otra forma en la que este núcleo contingente de indivisibilidad que afecta y divide actúa en el campo material del pensamiento de Lezra. No es casual

\footnotetext{
J. Lezra, Defective Institutions: or, Critique. Manuscrito enviado por el autor, p. 16.

18 Cf., J. Derrida, El problema de la génesis en la filosofia de Husserl, trad. Javier Bassas Vila, Ediciones Sígueme, Salamanca, 2015.

19 J. Lezra, "Uncontable Matters" en On the Nature of Marx's Things, New York, Fordham University Press, 2018, pp. 178-200.

20 J. Derrida, Fuerza de ley: el fundamento místico de la autoridad, trad. P. Peñalver, Madrid, Tecnos, 1997, p. 186.
} 
que el punto de partida de la teología política, al menos de la schmittiana, sea la definición de soberanía: "soberano es quien decide sobre el estado de excepción" Haciendo recaer la definición de soberanía (Souveränität) en el soberano (Souverän), Schmitt proporciona un modelo que permite pensar la estructura de la soberanía a partir del modelo de una decisión individual retomado de la enunciación católica y monárquica. El modelo que Lezra va a oponer a esta especulación decisionista es la frase freudiana "Wo Es war, soll Ich werden", que Freud emplea en sus "Nuevas conferencias de introducción al psicoanálisis" de 1932. Esta frase para señalar el específico "trabajo de cultura" (Kulturarbeit) del psicoanálisis, consiste en hacer advenir al yo sobre la alteridad radical del ello. Traducida al español ya sea como "Donde era ello, ha de ser yo" (López Ballesteros) o como "Donde Ello era, Yo debo devenir" (más acorde con el verbo werden, que ocupa un lugar fundamental en la sentencia original freudiana, por José Etcheverry) indica, a tono con el título de la conferencia ("La descomposición de la personalidad psíquica", aunque el término Zerlegung, traducido por descomposición, podría ser también partición: asunto retomado desde luego por la interpretación lacaniana) el tipo de división radical que afecta al sujeto, lo que Lezra lee correctamente como una excentricidad. Esta excentricidad, para Lezra, esta no-coincidencia del sujeto de sí a sí, sin embargo, enunciada ya de antemano en la escena preanalítica, primaria del "yo es yo" que está en la base del que se enuncia como soberano, es lo que permite leer la violencia teológico-política como momento de suturación de una contingencia radical entre "Ich" y "Es", entre yo y ello, a partir de un trazo de unión terapéutico ${ }^{22}$.

Respecto a este resto excéntrico, traigo a colación otro pasaje de Freud, desde luego importantísimo para el universo conceptual de Lezra, ubicable en otro texto tardío, el famoso "Moisés y la religión monoteísta" que Freud escribió en entregas entre 1934 y 1938. Dice Freud, respecto a los "otros" procesos anímicos que afectan al yo, habitualmente entendidos como inconscientes, que son "un Estado dentro del Estado, un partido inaccesible, inviable para el trabajo conjunto, pero que puede llegar a vencer al otro [...] se alcanza así el imperio de una realidad psíquica interior sobre la realidad del mundo interior" $(1991,73-74)^{23}$. Esta cita funciona en torno a dos metáforas. La primera de ellas es la del "Estado dentro de un Estado", y proviene de Spinoza. "Imperium in imperio", "imperio dentro de otro imperio" es el tipo de definición de lo humano que Spinoza quiere abandonar, en la medida en que dicha definición asume

C. Schmitt, Teología política, Madrid, Trotta, 2009, p. 13.

22 Cf. al respecto el artículo de Lezra "El caso del soberano en el inconsciente: la escena primaria de la teología política", Res Pública, 17, 1, 2014, pp.151-179. En torno a este texto, Lezra construye un argumento, a ratos incluso dramático -con todo lo que conlleva conectar a Freud con Schiller- para señalar cómo la relación, construida como equivalencial, entre teología y política -sobretodo en la escena schmittiana- depende de una traducción y de un proceso de censura. Las palabras que aquí menciono, traducción, censura, excentricidad, no dejan de estar definidas por un acercamiento a la teoría psicoanalítica freudiana

23 S. Freud, "Moisés y la religión monoteísta", trad. J.L. Etcheverry, en Obras completas, Buenos Aires, Amorrortu, 1991. pp. 73-74. que el hombre "tiene una potencia absoluta por sobre sus acciones" y no está dominando por el orden de la naturaleza ${ }^{24}$. Contra esta concepción absoluta-diríamos, para provocar un poco al debate teológico-político, absolutista- de la potentia Spinoza va a insistir en un "orden" de las cosas y los pensamientos, en un "ordo et connexio idearum" y en un "ordo et connexio rerum" que niega al hombre toda potestad absoluta sobre la naturaleza y sobre sus propias acciones ${ }^{25}$. El uso profano, provocativo de esta idea por parte de Freud conmina la posibilidad de que el hombre, que se considera "imperium in imperio" en la formulación de Spinoza, esté afectado por un imperio que le es completamente excéntrico. Desde luego, la distancia entre los términos "estado" (Staat) e "imperio" (Herrschaft) no puede ser suprimida, pero ambos pertenecen al horizonte de una profusa metaforicidad política. En torno a esta segunda metáfora se entreteje la proposición freudiana: el inconsciente se trata de la existencia de un partido (Partei) inaccesible (unzugängliche) que vuelve inviable o inútil (unbrauchbare) el trabajo conjunto, el imperio de una realidad psíquica interior (die Herrschaft einer inneren psychischen Realität), un estado dentro de otro estado, etc ${ }^{26}$. Este resto excéntrico es lo que también Lezra entiende como materia incontable, materia que no se puede contar, que resiste la simbolización.

La insistencia de esta materia es legible, para Lezra, en proposiciones tautológicas que muestran el inestable imperio de toda violencia de confirmación. "Dios es Dios", la tautología analizada por el filósofo y sacerdote francés Stanislas Breton, le sirve a Lezra para leer un tipo de juicio heterológico que sin embargo no se contenta con la pedagogía de otro tipo de subsunción -por ejemplo, "Dios es amor". Se trata de tautologías cuyo carácter explosivo incluiría un tipo de violencia, una desviación inicial. Me parece que una cierta homología filosófico-material queda instalada: los solida materiai de Lucrecio, aquellos elementos últimos indestructibles e indivisibles, son la condición de toda desviación. Lezra señala que a propósito de estas tautologías atómicas que existen como "proposiciones tautológicas en un sentido diferente al que estamos acostumbrados -y que subyacen a los principios de identidad, de no-contradicción, de razón suficiente" ${ }^{27}$. Para Breton -traducido al inglés por el propio Lezra- la tautología "Dios es Dios" funciona confirmando "la relación entre violencia y monoteísmo". Hay una fuerza explosiva, explica Breton, en esta sentencia aparentemente banal, en la medida en que esta repetición, Dios-Dios, es la que abre una experiencia de multiplicación ${ }^{28}$.

Una forma extenuada de esta tautología, explotada por otro referente del pensamiento lezreano, podría ayudarnos a leer mejor este problema, tan arduo, de la relación entre violencia e institución, entre desviación

\footnotetext{
B. Spinoza, Ética demostrada según el orden geométrico, Buenos Aires, FCE, 1958, p. 102.

Ibidem, p. 102.

26 S. Freud, op. cit., p. 124.

J. Lezra, op.cit. p. 22.

28 Me sirvo aquí de la traducción de Lezra: "God is God: Essay on the Violence of Tautological Propositions", The Yearbook of Comparative Literature, 61, 2015, pp. 203-211.
} 
instituyente y tautología. Me refiero aquí a la frase, citada a menudo por Althusser, "la teoría de Marx es todopoderosa porque es verdadera" ("La théorie de Marx est toute-puissante parece qu'elle est vraie") ${ }^{29}$. Esta sentencia dogmática constituye para Althusser una suerte de garantía: ella proviene de la necesidad de constatar que la filosofía es una lucha, y que, por tanto, hace falta retener la importancia de la posición teórica de un trabajo -y sólo a partir de ello, sería legible la transparencia de sus tesis. Dejo de lado la recurrencia de otras tesis a esta misma violencia instituyente, para concentrarme en esta cuasi-tautología althusseriana- cuasi en la medida en que no se confirma en la mera forma "x es x", sino que introduce una pequeñisima variación que va de lo todopoderoso a lo verdadero, del golpe de fuerza a la fuerza de la verdad ${ }^{30}$.

\section{3.}

Publicado en 1997, el ensayo "Althusser y la religión" de Stanislas Breton reinterpreta la escritura althusseriana en lectura inversa. Son los diarios de prisión (el Journal de Captivité escrito entre 1940 y 1945) los que otorgan a Breton una clave de lectura diferente de la del estructuralismo, o inclusive aquella del materialismo aleatorio. Breton pone énfasis en un problema más bien referente a la teoría althusseriana de la coyuntura, el problema del "vacío de una toma de distancia":

Althusser me sugirió que leyera El Príncipe de Maquiavelo. Siguiendo su sugerencia, le planteé mis conclusiones: en contraposición a los filósofos que se preguntan ordinariamente sobre la esencia de la política, Maquiavelo, le dije, está solamente interesado en la casuística. Estudia casos y se lo limita a lo circunstancial ${ }^{31}$.

En un giro notable, el sacerdote amigo de Althusser, vincula esta mirada casuística, circunstancial, coyuntural, con el problema del vacío. Pensamiento del vacío de una toma de distancia, en definitiva, vacío "famoso bajo las especies del silencio y de las islas desiertas, imágenes del mar y de su silencio, imágenes de juventud: quiero creer que aun en sus días finales, ellas nunca lo abandonaron"32. ¿No podríamos leer este vacío de una toma de distancia como aquello que se abre en la proposición tautológica?, ¿no es la tautología el inicio de

29 L. Althusser, "Soutenance d'Amiens (1975)" en Solitude de Machiavel. París, PUF, 1998, pp. 200-236.

30 Me refiero, desde luego, a la frase de Derrida "tout autre est tout autre", traducida al español como "cualquier/radicalmente otro es cualquier/radicalmente otro". Aquí la cita que Jacques Lezra -también- cita en un pie de página fundamental de su traducción del mencionado texto de Breton: "«Cualquier/radicalmente otro es cualquier/ radicalmente otro»: todo lo que aquí está en juego parece afectado por el temblor de esta fórmula. Esta resulta demasiado económica, sin duda, demasiado elíptica, y por ello, como toda fórmula aislada, transmisible fuera de su contexto, recordando casi el lenguaje cifrado de una contraseña. En dicha fórmula se juega con reglas, se abrevia, se corta violentamente un campo de discurso" en "God is God, Essay on the Violence of Tautological Propositions", The Yearbook of Comparative Literature, Volume 61, 2015, pp. 203-211.

31 S. Breton, "Althusser and Religion" en A. Hamza, Althusser and Theology, Londres, Haymarket Books, 2018, pp. 16-17.

32 Idem. una violencia circunstancial, como dice Breton, habitada por imágenes del silencio, de lo casual? La sentencia dogmática de suyo "la teoría de Marx es todopoderosa porque es verdadera" tiene la forma banal y tautológica del tipo "Dios es Dios". La explicación althusseriana no pretende dejarnos satisfechos -lo que podría hacerse estableciendo una diferenciación entre los valores teóricos de lo verdadero y lo todopoderoso- sino más bien insistir, repetir la violencia constitutiva de la frase: "no es porque está verificada por sus éxitos y fracasos que es verdadera, sino porque es verdadera que es verificable por sus éxitos y fracasos" ${ }^{33}$.

Decir que algo es todopoderoso porque es verdadero es, en efecto, similar a decir que un libro es bueno porque es fantástico, que un lápiz es excelente porque es maravilloso, etc. El atributo de verdad otorgado a la teoría de Marx es lo que la hace poderosa, es decir, su capacidad de autoafirmarse sin relación con un campo de verificación que le sea adecuado. Aun más: para Althusser el campo de inadecuación aleatorio del concepto de lo verdadero no hace sino hacerlo más verdadero, etc., y aquí se haya uno de los temas centrales del "concepto defectivo" de Jacques Lezra, particularmente en Materialismo salvaje. Althusser vincula la violencia constitutiva de esta frase cuasi-tautológica y sus propias conclusiones con una "ley del exceso" que estaría en la base de toda tesis filosófica. La tautología bretoniana de Dios es Dios y la cuasi-tautología althusseriana que hace equivalentes a la verdad y al marxismo, abren y producen como efecto, en su propio exceso violento, una contingencia material abierta a lo múltiple. Eso es lo que, en la lectura radical de Lenin y la filosofía, Althusser lee como "toma de partido" en filosofía ${ }^{34}$. Nótese aquí lo que, partido, toma de partido, posicionalidad, exceso, quieren decir. Se sitúan por fuera del horizonte simbólico de la dialéctica del significante-amo, por fuera incluso de las exigencias de fidelidad y de lealtad que están en la base de una prognosis estatista y estalinista. Se trata más bien del "golpe de fuerza" que Derrida, precisamente en uno de sus diálogos más notorios sobre el pensamiento althusseriano -Positions de 1972- concita a propósito de la pregunta por la "toma de partido" en filosofía: "rien me «choque» moins", nada me choca menos, escribe Derrida a Jean-Louis Houdebine, que esta idea de toma de partido en filosofía. Desde luego, se trata de enfatizar el gesto deconstructivo como noneutral, como inscrito, en primer lugar, y posicional, en segundo. Entendiendo la posición como ese "coup de force", golpe de fuerza, incluso como "irreductibilidad del espaciamiento" que afecta originariamente a la posición $^{35}$. Posición, violencia de una proposición tautológica, toma de partido -“unzugängliche Partei”, según vimos con Freud- son las condiciones de un pensamiento aleatorio sobre la materialidad institucional, ¿y por qué no pensarlo también, siguiendo a Breton, a partir de las imágenes del mar, del silencio?, ¿no es precisamente el silencio oceánico aquello que abre una toma de distan-

\footnotetext{
L. Althusser, op. cit., p. 174

34 L, Althusser, Lenin y la filosofia, Buenos Aires, Ediciones CEPE, 1972 , p. 65 ss.

35 J. Derrida, Positions, Paris, PUF, 1972, pp. 130-132.
} 
cia? Los efectos de ese vacío retoman lo más intenso del gesto sadeano, o sádico. Sade representa al mismo tiempo el límite y el exceso del terror revolucionario, ahí donde resiste las formas de mediación que lo vuelven solidario al derecho ${ }^{36}$. La frase, aparentemente dogmática, polémica, insostenible y auto-referencial -tautológica, en definitiva- "el marxismo es todopoderoso porque es verdadero" cumple así la función de una desviación, de una curvatura, el vacío de una toma de distancia -la construcción, en todo caso, de una posición.

Quisiera leer la operación de Lezra respecto a Sade como una interesada en deshacer el nudo complejo que Lacan identifica entre ley y transgresión, entre cumplimiento puntilloso del imperativo jurídico, legal, normativo y plus de goce, para ir a un momento de determinación anterior en el gesto sádico. Mientras que la motivación básica del "Kant con Sade" es, en efecto, leer el erotismo de la ley moral, el goce que existe y se presenta en el acto mismo de rechazar las formas de reciprocidad eróticas $^{37}$, para Lezra se trata de encontrar la posibilidad de un "momento de ceguera" 38 . No me puedo detener en lo que considero una profunda compatibilidad de ambas lecturas, que sin embargo asumen direcciones distintas. Más bien quisiera mostrar el resultado específico del debate que se propone iniciar Lezra.

\section{4.}

El final del Kant con Sade de Lacan termina confirmando la sumisión de Sade a la ley, desde luego, a partir de la prohibición -que Lezra denomina teológico-edípica- de la madre en La filosofía en el tocador. Hay un nivel de oposición con las lecturas en boga sobre Sade en el pensamiento francés de la primera mitad del siglo $\mathrm{XX}$, de las que el ensayo de Lacan parece ser un resultado -por lo demás bastante perverso. Particularmente su seminario VII, La ética del psicoanálisis ${ }^{39}$ enuncia el sentido programático de una diferencia teórica con

36 En este sentido, también puede señalarse, sin lugar a duda, la referencia benjaminiana del trabajo de Lezra. Benjamin es el autor de un tipo de violencia, "letal e incruenta" que se piensa y se despliega al mismo tiempo como crítica, como crítica de la violencia y como violencia crítica. El trabajo de Lezra en este sentido hace juego con la escena benjaminiana chilena y con autores como Pablo Oyarzún y Willy Thayer.

37 J. Lacan, Escritos, Buenos Aires, trad. Tomás Segovia, Siglo XXI, 2005, pp. 744-770.

38 J. Lezra, "Sade on Pontecorvo", Discourse, 25, 3, Fall 2003, pp. 4875 .

39 Cf. J. Lacan, La ética del psicoanálisis, Buenos Aires, Paidos, 2001. Sobre el imperativo kantiano, Lacan escribe: "la ley moral como principio de la determinación de la voluntad, perjudica por ello mismo todas nuestras inclinaciones, y debe producir un sentimiento que puede ser llamado de dolor. Y este es el primero, y quizás el único caso, en que nos esté permitido determinar, por conceptos, a priori, la relación de un conocimiento, que surge así de la razón pura práctica, con el sentimiento de placer o de pena. [En suma], Kant es de la opinión de Sade. Para alcanzar absolutamente das Ding, para abrir todas las compuertas del deseo, ¿qué nos muestra Sade en el horizonte? Esencialmente, en el dolor", pp. 98-99. Esta denegación de lo imaginario en el deseo como deseo de la ley podría ser la definición misma del "goce" sádico - que no es otra cosa, para Lacan, que goce de la ley. Antes que la ley, sin embargo, Lezra aparece aquí interesado en la contingencia y los posibles efectos que ella teje, a saber, lo que llamamos "ley" como cuajamiento de un desvío, etc. la escena francesa, interesada en leer a Sade como el reverso de la ley $-\mathrm{y}$ sólo a partir de esa condición primaria, desatar conclusiones: reaccionario/monarquista, moderno/ilustrado o bien el primer despunte de un tipo de soberanía anti-edípica, etc. Si hubo en autores como Simone de Beauvoir y Klossowski una voluntad similar -aunque en tensión- de leer el gesto sadeano como el de una apología de la revolución, como presencia eterna del crimen, o como el colmo de la transgresión en Bataille, en Lacan se confirma en cambio la tesis inédita de una copertenencia entre la máxima transgresión sádica y la ley. El Kant con Sade de Lacan se configura, de esta manera, como un espacio jeroglífico en el que se pueden leer los debates acerca de la sumisión, o no, de Sade a algún tipo de ley -particularmente a la ley del padre. Desde luego, al psicoanálisis le tocó desde un principio jugar un rol principal, y ello es particularmente patente en el debate iniciado por Klossowski, para quien Sade no sólo se somete a la ley, sino que la produce en una producción supra-masculina de agresividad anti-materna $^{40}$. La influencia de esta lectura de Klossowski en la recepción deleuziana de Sade es igualmente innegable. La "adoración del padre destructor" sádica tiene como contraparte la alianza insólita entre el masoquista y la madre. Casualmente, hay un empalme entre la lectura de Simone de Beauvoir y Lacan tan evidente como lo hay entre Klossowski y Deleuze: si de Beauvoir en 1953 se anticipaba a Lacan diciendo que Kant pertenece a la misma severidad y tradición puritana que Sade, Klossowski lo inscribe entre los autores de un monarquismo fálico y destructor de la naturaleza materna y femenina ${ }^{41}$.

El giro operado por Lezra a propósito de estos debates consiste en preguntarse más bien por los efectos del gesto sádico en su materialidad táctil. El sentido de la conminación sádica - "un esfuerzo más por ser republicanos"- sería el de una lógica de los encuentros. Lo que evita al mismo tiempo el debate sobre el imperativo, que está presente en toda la tradición señalada, y la reivindicación del sadismo como transgresión maestra. Lo que me parece clave aquí es como un texto, publicado primero como artículo en 2003, y luego incluido en Materialismo salvaje, se toma en serio la iniciativa de Deleuze: diferenciar dos formas opuestas de desexualización y

P. Klossowski, Sade mi prójimo/El filósofo malvado, trad. G. de Sola, Buenos Aires, Editorial Sudamericana, 1970, p. 136.

41 Aunque la lectura lacaniana parta de hecho por mostrarse como una excepción a la tradición de lectura francesa, incluyendo -o quizás enfatizando- el texto de Simone de Beauvoir, ¿Hay que quemar a Sade?, libro alucinante no sólo por su anticipación prístina a toda la reflexión lacaniana sino por aquello que pone sobre la mesa -la transformación más intensiva de la ética en política es la que realiza el sadismo: fuera de la ética no hay emancipación posible en Sadeexhibe hipótesis parecidas a las de Lacan, allende su capacidad para darse juego con el texto de Kant y Lacan en un mismo hilo: el sadismo "vuelve vanas todas las satisfacciones contingentes que estaríamos tentados de extraer" de la virtud -aun de la virtud sexual, la devoción, el amor romántico, etc.: "Mediante una severidad análoga a la de Kant y que tiene su fuente en una misma tradición puritana, Sade sólo concibe el acto libre redimido de toda sensibilidad: si obedeciese a motivos afectivos, haría de nosotros esclavos de la naturaleza y no sujetos autónomos". S. de Beauvoir, ¿Hay que quemar a Sade? Trad. F. Sampedro, Madrid, Editorial Mínimi Tránsito, 2000, p. 91. 
resexualización ${ }^{42}$. Para Lezra, la operación de Sade está relacionada con "la manera en que un acto, un juicio, un concepto o un cuerpo invade, usurpa, define, depende de otro cuerpo, es contingente respecto a él"43. En Sade, ese encuentro contingente adquiere la forma de una ceguera, de un "intervalo en que la teoría y la práctica son ciegas la una a la otra" ${ }^{44}$. Esta "errancia ciega" de los personajes sadeanos, especialmente de Eugénie, quien cierra los ojos mientras cose a su madre, constituye una metáfora literaria de la fundación, especialmente de la fundación institucional o instituyente: el intervalo de ceguera en el que la producción de un cuerpo cerrado, cosido, avanza a puntadas ocurriendo y fundando lo político.

Recuerdo en este punto la lectura deleuziana: mientras que Sacher-Masoch es el autor del contrato, de la forma-contrato que asume, sino la reciprocidad, la estrategia sexual, erótica consistente en ponerse en el lugar del padre maltratado, eliminado, subastado por una fuerza maternal desatada en su violencia, el Marqués de Sade es el autor de la institución. Esta diferenciación virtual entre institución y contrato resulta fundamental si se quiere capturar el gesto del institucionalismo defectivo de Jacques Lezra. Si el pensamiento de Sade es institucionalista, es porque la institución, para Deleuze, "define en general un estatuto de larga duración, involuntario e intransferible, estatuto constitutivo de un poder, de una potencia y cuyo efecto puede ponerse a terceros" $"$. Los motivos de la "insurrección permanente" que configuran el locus criminal del sadismo -según Klossowski y Deleuze- se encarnarían en esta suerte de momento de institucionalismo anárquico. Simone de Beauvoir había analizado muy bien ese otro borde del sadismo: aquel en el que se muestra como contrario a la revolución, no por su ausencia de radicalidad, sino por su capacidad para capturar una emergencia anárquica que, paradójicamente, se presenta al mismo tiempo como conservadora. Sade "extrema esta concepción", dice Deleuze, según la cual la revolución, empalmando la ley y el contrato con la ideología del terror, traiciona al espíritu verdadero de la república. "El Terror -señala De Beauvoir- que es ejercido con buena conciencia, constituye la más radical negación del mundo demoníaco de Sade"46. "Matar sin juzgar" sería la máxima del sadismo. Esta muerte sin juicio, pensada como radicalización de la república, ¿tiene algo que ver con el institucionalismo defectivo de Lezra? Si para Deleuze el problema sádico por excelencia es el de las "instituciones sin leyes, anárquicas, en movimiento perpetuo, en revolución permanente, en estado de inmoralidad constante" 47 , es porque sólo puede realizar dicho entramado institucional en revolución permanente mediante la institucionalización del crimen. La saturación ética del pensamiento de Sade aquí apa-

\footnotetext{
42 G. Deleuze, Presentación de Sacher-Masoch, lo frio y lo cruel, trad. I. Agoff, Buenos Aires, Amorrortu, 2001.

43 J. Lezra, Materialismo salvaje: La ética del terror y la república moderna, trad. J. Rodríguez Fernández, Madrid, Biblioteca Nueva, 2012 , p. 257. Cito aquí una versión española, modificada, del más arriba citado "Sade on Pontecorvo".

44 Ibidem, p. 260

45 G. Deleuze, op. cit., p. 82.

46 S. de Beauvoir, op. cit., 52.

47 G. Deleuze, op. cit., p. 84.
}

rece más vívidamente, como el atolladero propio de la recepción francesa de su pensamiento y de su obra. Sólo instituciones morales -es decir, inmorales- pueden adquirir la espesura de la insurrección permanente esperada por Sade. En cambio, el sadismo de Lezra nos recuerda a las puntadas y al "hilo rojo" de la contingencia. En otros términos, desplaza la pregunta por la violencia de su estructuración ético-moral.

\section{5.}

Mi propia intervención en este entramado conceptual, material, en el "hilo rojo" de la contingencia ciega-del materialismo aleatorio, lucreciano de Jacques Lezraconsiste en ubicar la relación del concepto defectivo de "institución" con un momento de no-mediación, de indeterminación que Althusser entiende como posicionalidad. Si hay algo inaceptable en la posición teórica de Althusser es la profusa metaforicidad política, combativa de sus conceptos. ¿No es precisamente esta posicionalidad, no-mediada, violentamente productiva de efectos de constitución/institución defectiva, lo que la crítica dialéctica, hegeliana, rechaza tajantemente bajo el nombre de Terror (Schrecken)? Hegel identifica el terror, de hecho, con la crueldad -sádica- y las formas de imposición cercanas a la muerte: el "punto" (Punkt) de la libertad absoluta es también la muerte más absoluta y aplanadora (kälteste, platteste Tod $)^{48}$. Es el giro althusseriano el que nos permite experimentar el terror, en cambio, como posicionalidad defectiva. Por eso las metáforas de la fuerza, del golpe de fuerza siguen siendo las fundamentales. La cuasi-tautología leninista que hace equivalentes al marxismo con lo todopoderoso-verdadero, opera en el contexto de una operación de fuerza-que no esconde su violencia: se trata de doblar el bastón, de curvar el bastón en sentido contrario ahí donde se encuentra desviado. Desviación que no se muestra como el efecto de una naturaleza contranormativa. La desviación es la condición misma de cualquier situación: "desigualdad de los orígenes", "origen afirmado-denegado: la primera forma de un concepto que Derrida introdujo en la reflexión filosófica, borradura [rature]"49. La curvatura del bastón entonces es una desviación de origen, una borradura que la fuerza de un golpe, un "coup de force" viene a forzar. Si ha escogido metáforas de fuerzas, situaciones cuasi-tautológicas, es "no por el placer de la provocación, sino para alertar a los lectores sobre esa relación de fuerza, para provocarlos a ellos y para producir efectos definidos" (por produire des effects définis), ya que "esa relación de fuerzas es el "exceso de la formulación de una tesis" $"$. Contracurvatura y desviación señalan entonces un punto, Punkt, que permiten pensar la institución y lo instituyente como desviación, como

\footnotetext{
G.W.F. Hegel., Fenomenología del espíritu, México, FCE, pp. 347 ss. Como las suspicacias abundan para asuntos de traducción cuando se trata de Hegel, me sirvo también aquí, del mismo autor, de: Phäenomenologie des Geistes, Werke 3, suhrkamp taschenbuch wissenschaft, Berlín, Suhrkamp, 1986.

49 L. Althusser, "The Humanist Controversy" en The Humanist Controversy and Other Writings, London, Verso, 2003, p. 241.

$50 \quad$ L. Althusser, "Soutenance", op. cit. p. 176.
} 
curvatura, como clinamen -y ello en contra de toda una tradición aristotélica que va a considerar la madeja institucional como un concilium medii (Lucrecio). Por eso se intuye que, desde siempre, la posicionalidad es defectiva como efecto de una fuerza puntual, desviada, que en términos lucrecianos puede ofrecernos la potencia de un vacío-inanis ${ }^{51}$. Con sus metáforas del bastón, de la curvatura, de la fuerza y del golpe, así como con su compromiso, táctico o no, con un tipo de terror que hubiese producido en Sade el mismo estupor -un terror que se piensa lejos de la violencia conservadora de derecho de la revolución francesa, y que no se deja atrapar en las figuras de la mediación y el Aufhebung- me pregunto también si no es la posicionalidad althusseriana productora de unos efectos de "comunidad sadeana", como dice Lezra, diferente del sadismo de la ley analizado por Lacan.

La lectura de Lezra respecto a estos conceptos específicos -institución, tautología, sadismo- efectúa, en su propia performance y en los trazos que manifiesta su despliegue, el vacío de una toma de distancia. Muestra el carácter profundamente circunstancial, contingencial de lo instituyente. Su irreductibilidad ya sea al horizonte de una república del crimen, o a la esfera del derecho como encarnación ordenadora de los universales, expresa la posibilidad de una insistencia posicional aleatoria. Al contrario que en la lógica de Fernando Atria, para quien las instituciones vienen a suplir un defecto previo correspondiente a la naturaleza humana y la existencia contrafáctica de los ideales-de libertad, socialismo, igualdad, etc. - en Lezra se trata de entender que las instituciones son ellas mismas el índice defectivo, abierto a lo porvenir, de una situación imposible- la de enunciar una posición en la violencia tautológica de un "esto es esto", de un "la teoría de Marx es verdadera", de un "Dios es Dios": en estas situaciones habita lo imposible. Hegel habría dicho de esta violencia imposible: "Punktualität", momento de una fría universalidad ( $k a l$ te Allgemenheit), terror como abstracción extrema. El prurito de la mediación, en la dialéctica hegeliana, debe siempre superponerse a la posición. Cuando insiste en su materialidad, en cambio, la posición es la que crea efectos contingentes, imprevisibles, pre-dialécticas. Es constituyente de instituciones defectivas.

\section{Bibliografía}

Althusser, L., "Soutenance d'Amiens (1975)" en Solitude de Machiavel. París, PUF, 1998.

-, “The Humanist Controversy" en The Humanist Controversy and Other Writings, London, Verso, 2003.

Althusser, L., Lenin y la filosofia, Buenos Aires, Ediciones CEPE, 1972.

Atria, F., "Sobre la soberanía y lo político", Derecho y humanidades, 12, 2006

-, "Socialismo hayekiano", Revista de Estudios Públicos, 2011, pp. 49-155.

-, Razón bruta, Edición digital, 2018.

Breton, S., "Althusser and Religion" en A. Hamza, Althusser and Theology, London, Haymarket Books, 2018.

-, "God is God: Essay on the Violence of Tautological Propositions", The Yearbook of Comparative Literature, 61, 2015, pp. 203-211, trad. J. Lezra.

De Beauvoir, S., ¿Hay que quemar a Sade?, trad. F. Sampedro Madrid, Editorial Mínimi Tránsito, 2000.

Deleuze, G., Presentación de Sacher-Masoch, lo frío y lo cruel, trad. I. Agoff, Buenos Aires, Amorrortu, 2001.

Derrida, J., El problema de la génesis en la filosofia de Husserl, trad. Javier Bassas Vila Salamanca, Ediciones Sígueme, 2015.

-, Fuerza de ley: el fundamento místico de la autoridad, trad. P. Peñalver, Madrid, Tecnos, 1997.

-, "La mitología blanca, la metáfora en el texto filosófico", Márgenes de la filosofía, Madrid, Cátedra, 2008.

-, Positions, Paris, PUF, 1972

Freud, S., "Moisés y la religión monoteísta", trad. J.L. Etcheverry, en Obras completas, Buenos Aires, Amorrortu, 1991.

G.W.F. Hegel., Fenomenología del espiritu, México, FCE, 2001.

Klossowski P., Sade mi prójimo/El filósofo malvado, trad. G. de Sola, Buenos Aires, Editorial Sudamericana, 1970.

Lacan, J., Escritos, trad. Tomás Segovia, Buenos Aires, Siglo XXI, 2005.

-, La ética del psicoanálisis, Buenos Aires, Paidos, 2001.

Lezra, J., Corpora Caeca: Discontinuous Sovereignty in The Prince. Manuscrito enviado por el autor.

-, "El caso del soberano en el inconsciente: la escena primaria de la teología política", Res Pública, 17, 1, 2014, pp.151-179.

-, Materialismo salvaje: La ética del terror y la república moderna, trad. J. Rodríguez Fernández, Madrid, Biblioteca Nueva, 2012.

-, "Sade on Pontecorvo" en Discourse, 25, 3, 2003, pp. 48-75, Wayne State UP.

-, "Uncountable Matters" en On the Nature of Marx's Things, New York, Fordham University Press, 2018.

Negri, A., El poder constituyente, trad. S. Frabotta y R. Sánchez Cedillo, Madrid, Traficantes de sueños, 2014.

Pettit, P., Republicanism: A Theory of Freedom and Government, Oxford, Oxford University Press 1997.

Pockock J., El momento maquiavélico, trad. E. García López y M. Vázquez-Pimentel, Madrid, Tecnos, 2002.

Schmitt, C., Teología política. Madrid, Trotta, 2009.

Spinoza B., Ética demostrada según el orden geométrico, Buenos Aires, FCE, 1958.

Vatter M., Between Form and Event: Machiavelli's Theory of Political Freedom, Países bajos, Springer Netherlands, 2000.

\footnotetext{
1 En la traducción de Valentí Fiol, para las mismas líneas del "De Rerum Natura" que citamos como epígrafe de este trabajo: "Así pues, existe un espacio impalpable, inocupado, vacío. Que si no existiera, de ningún modo podrían moverse las cosas, pues la función propia de la materia, esto es, chocar y ofrecer resistencia, actuaría a cada momento en todo objeto; ninguno podría por tanto avanzar" (I, 335-340).
} 